\title{
Mersin İlinde Çiftçilerin Tarımsal Kredi Kullanım Kararlarını Etkileyen Faktörler
}

\author{
Seyit HAYRAN ${ }^{1}$, Aykut GÜL ${ }^{1}$
}

ÖZET: Bu araştırmanın amacı Mersin İli'nde çiftçilerin tarımsal kredi kullanım kararlarına etki eden faktörleri belirlemektir. Araştırma verileri çok aşamalı rastgele örnekleme tekniği ile belirlenen 239 çiftçiden toplanmıştır. Araştırma verileri tanımlayıcı istatistikler ve ikili lojistik regresyon analizi ile değerlendirilmiştir. Bu araştırmada çiftçilerin bazı sosyoekonomik özelliklerinin ve bilgi arama davranışlarının kredi kullanma kararlarını etkilediği belirlenmiştir. Aile genişliği, işlenen arazi miktarı, kooperatif ortaklığı ve yazılı materyal okuma değişkenleri çiftçilerin tarımsal kredi kullanımlarını pozitif; çiftçinin yaşı, serbest tarım danışmanlığı hizmeti alıp almama ve son bir yılda katıldığı tarımsal eğitim programı sayısı değişkenleri ise negatif yönde etkilemektedir.

Anahtar Kelimeler: İkili lojistik regresyon, kredi, Mersin, tarım.

\section{Factors Affecting Farmers' Decisions on Agricultural Credit Usage in Mersin Province}

\begin{abstract}
The purpose of this study was to determine the factors affecting farmers' decisions on the use of agricultural credit in Mersin Province. The research data were collected from 239 farmers selected by multistage random sampling technique. The research data were evaluated by descriptive statistics and binary logistic regression analysis. In this study, it was determined that farmers' some socioeconomic characteristics and information seeking behaviors affected their decisions on credit usage. Family size, farmland size, cooperative partnership, and printed material reading variables affected farmers' use of agricultural credits positively; age of farmers, whether or not they receive free agricultural counseling service, and the number of agricultural training programs attended in the last year affected it negatively.
\end{abstract}

Keywords: Binary Logistics Regression, credit, Mersin, agriculture.

\footnotetext{
Seyit HAYRAN (0000-0002-0223-8034), Aykut GÜL (0000-0002-8708-8433), Çukurova Üniversitesi, Ziraat Fakültesi, Tarım Ekonomisi, Adana, Turkey

Sorumlu yazar/Corresponding Author Seyit HAYRAN, shayran@cu.edu.tr
} 


\section{GíRiş}

Sahip olduğu tarımsal arazinin hem miktar hem de toplam yüzölçümüne oranı bakımından Türkiye, dünyanın en geniş ülkelerinden birisidir. Ülke topraklarının yaklaşık \%35.50'si işlenebilir arazilerden oluşurken, yaklaşık \%15.00'i de orman arazilerinden oluşmaktadır. Türkiye sahip olduğu toplam 23.630.000 ha tarla ve bahçe arazisi ile bu alanda dünyanın en geniş 14. ülkesidir (İzmir Ticaret Borsası, 2014). Yaklaşık 24 milyon hektar tarım arazisine sahip olan Türkiye, 2016 yılı itibariyle toplam gayrisafi yurt içi hasılasının yaklaşık \%8.00'ini tarımdan elde etmiş ve toplam ihracatının da yaklaşık \%11.50'sini tarımdan gerçekleştirmiştir. Türkiye'de istihdamın yaklaşık $\% 20$ .00 'si de tarım sektörü tarafından oluşturulmaktadır (Engürülü, 2017). Tarımsal potansiyeli oldukça yüksek olan Türkiye, başta küçük ve paçalı işletmeler, eğitim seviyesi düşük çiftçi yapısı ve modern tarımsal girdi, alet ve ekipmanlara ulaşmada yetersiz kalan finansman gibi karşı karşıya kaldığ 1 çeşitli sorunlar nedeniyle bu potansiyelini tam olarak kullanamamaktadır (Doğan ve ark., 2015).

Türkiye tarımının en önemli sorunlarından birisi çiftçilerin gerekli zamanda ve ihtiyaç duydukları miktarda krediye erişim imkanlarının zayıf olmasıdır (Özçelik ve ark., 2005). Tarımda kredi kullanımı üretim miktarının, verimliliğin, girdi kullanım etkinliğinin ve nihayetinde tarımsal gelirin artırılması için oldukça önemlidir (Bozoglu and Ceyhan, 2007; Terin ve ark., 2014). Her ne kadar iyi motive edilmiş ve eğitimli olursa olsun, yeterli finans kaynağından yoksun olan bir çiftçinin modern tarım yapma imkânı yoktur. Çünkü modern tarım verimli tohum/tohumluk, gübre, tarımsal ilaç, kesif hayvan yemi, belli konularda uzman işgücü gibi girdilerin kullanımını gerektirmektedir. Bunların uygun zaman ve yeterli miktarda temin edilebilmesi ise sürekli bir nakit çıkışına yol açmaktadır. Ancak tarımın yapısı nedeniyle, çiftçiler sürekli bir nakit çıkışı ile karşı karşıya olmalarına rağmen, hasat dönemine bağlı olarak yılda bir ya da birkaç kez gelir elde edebilmektedirler (Özçelik ve ark., 2005). Bu durum çiftçilerin tarımsal destekler, sübvansiyonlar ve kredi gibi çeșitli yollarla finanse edilmelerini zorunlu kılmaktadır. Çiftçilerin gerekli zaman ve yeterli miktarda krediye erişebilmeleri tarımsal aktivitelerini geliştirebilmelerine ve modern teknolojileri uygulayabilmelerine yardımcı olabilir (Bülbül, 2006).
$\mathrm{Bu}$ denli önemli olmasına rağmen Türkiye'de tarımsal kredilerin öncelikli olarak, tarımsal üretimin geliştirilmesi, uygun toprak hazırlı̆̆ı, diğer işlemler için modern girdi ve makine/ekipman temini için ihtiyaç duyan ve bu konularda hassas çiftçilere yönlendirilmesi için uygulamalar oldukça yetersizdir. $\mathrm{Bu}$ nedenle çiftçilerin tarımsal kredi kullanımlarını etkileyen faktörlerin belirlenmesi hem kredi politikaları ile ilgili uygulayıcılar hem de kredi tedarikçileri için önemlidir. Ancak Türkiye'de çiftçilerin tarımsal kredi kullanımlarını etkileyen faktörlerin incelendiği literatür oldukça yetersizdir (Kizilaslan and Adiguzel, 2007; Aksoy ve ark., 2010; Gunes et al., 2016; Gunes and Movassaghi, 2017). Bu çalışmayla Mersin İlinde çiftçilerin sosyoekonomik özellikleri ve bilgi arama davranışlarını da tanımlayarak, kredi kullanım kararlarına etki eden faktörleri belirlemek amaçlanmıştır.

\section{MATERYAL VE YÖNTEM}

\section{Materyal}

Araştırmada kullanılan birincil veriler Mersin İli'nin Akdeniz, Anamur, Gülnar, Mezitli, Mut, Silifke, Tarsus, Toroslar ve Yenişehir ilçelerinden çok aşamalı rastgele örnekleme tekniği ile belirlenen 239 üreticiden anket yöntemi ile 2017 Yılının Haziran ayında toplanmıştır. Araştırma toplam 40 köyde yürütülmüştür. Toplam köy sayısı ilçelere oransal olarak (Her ilçedeki köy sayısının toplam köy sayısına oranı baz alınarak) dağıttılmış ve her köyde 6'şar anket yapılarak toplam 240 üreticiye ulaşı1mıştır. Ancak bir ankette elde edilen cevapların eksikliği nedeniyle değerlendirmeler toplam 239 üretici üzerinden yapılmıştır. Ayrıca araştırmada daha önce konu ile ilgili yapılmış bilimsel eserlerden de yararlanılmıştır.

\section{Yöntem}

Bağımlı değişkenin yalnızca iki değer (1 - 0 gibi) aldığı durumlarda kullanılacak olan modeller sınırlıdır. $\mathrm{Bu}$ araştırmada istatistik yöntem olarak ikili lojistik regresyon analizi kullanılmıştır. Lojistik regresyon analizinin temel amacı en az değişkeni kullanarak, bağımlı ve bağımsız değişkenler arasındaki ilişkiyi belirlemektir. Analizde bağımlı değişken kesikli bir değer almakta ve bu analiz ile bağımlı değişkenin alabileceği değerlerden birinin gerçekleşme olasıllığı tahmin edilmektedir. Ayrıca lojistik regresyon analizi 
çok değişkenli normal dağılım şartı da aramamaktadır (Hair et al., 1994; Kalayc1, 2008; Alpar, 2011).

Üreticilerin tarımsal kredi kullanım kararlarına etki eden faktörleri belirlemek için kurulan modele dâhil edilen değişkenler, bunların tanımları, ölçüm düzeyleri ve tanımlayıcı istatistikleri çizelge 1 'de gösterilmiştir. Araştırmada üreticilerin 2016-2017 üretim döneminde kredi kullanım durumları bağımlı değişken olarak alınmıştır. Bağımsız değişkenler olarak ise üreticinin yaşı, eğitimi, hane genişliği, işlenen arazi miktarı, kooperatif ortaklığı, tarım sigortası yaptırma durumu, serbest tarımsal danışmanlık hizmeti alıp almaması, son bir yılda katıldığı tarımsal eğitim sayısı, son bir ayda tarımsal kitap, broşür gibi yazılı materyal okuyup okumaması alınmıştır.

Çizelge 1. Lojistik regresyon analizinde kullanılan değişkenler

\begin{tabular}{|l|l|c|c|c|c|}
\hline Değişken & Değişken Tanımı ve Ölçüm Düzeyi & $\begin{array}{c}\text { En } \\
\text { Düşük }\end{array}$ & $\begin{array}{c}\text { En } \\
\text { Yüksek }\end{array}$ & Ortalama & $\begin{array}{c}\text { Std. } \\
\text { Sapma }\end{array}$ \\
\hline Kredi & $\begin{array}{l}\text { Tarımsal kredi kullanımı } \\
\text { (1 evet; 0 hayır) }\end{array}$ & 0 & 1 & 0.31 & 0.47 \\
\hline Yaş & Çifţ̧inin yaşı (yıl) & 18 & 81 & 47.77 & 13.35 \\
\hline Eğitim & Çiftçinin eğitim süresi (yıl) & 0 & 17 & 7.85 & 3.39 \\
\hline Birey & Hane genişliği (kişi) & 1 & 10 & 4.25 & 1.49 \\
\hline Arazi & İşlenen toplam arazi miktarı (da) & 0.5 & 620 & 35.92 & 61.69 \\
\hline Kooperatif & $\begin{array}{l}\text { Kooperatif ortaklığı } \\
(1 \text { evet; 0 hayır) }\end{array}$ & 0 & 1 & 0.27 & 0.45 \\
\hline Sigorta & $\begin{array}{l}\text { Tarım sigortası yaptırma } \\
\text { (1 evet; 0 hayır) }\end{array}$ & 0 & 1 & 0.23 & 0.42 \\
\hline Danışman & $\begin{array}{l}\text { Serbest tarımsal danışmanlık hizmeti alma (1 evet; } 0 \\
\text { hayır) }\end{array}$ & 0 & 1 & 0.10 & 0.30 \\
\hline $\begin{array}{l}\text { Tarımsal } \\
\text { Eğitim }\end{array}$ & Son bir yylda katıldı̆̆ı tarımsal eğitim sayısı (adet) & 0 & 5 & 0.32 & 0.82 \\
\hline $\begin{array}{l}\text { Yazılı } \\
\text { Materyal }\end{array}$ & $\begin{array}{l}\text { Son bir ayda tarımsal kitap, broşür gibi yazılı materyal } \\
\text { okuma durumu (1 evet; 0 hayır) }\end{array}$ & 0 & 1 & 0.46 & 0.50 \\
\hline
\end{tabular}

\section{BULGULAR VE TARTIŞMA}

Üreticilerin Sosyoekonomik Özellikleri ve Bilgi Arama Davranışları

Anket yapılan çiftçilerin tamamı erkektir. Araştırma anketlerinin işletme yöneticisi ile yapılmış olması ve işletme yönetici konumunda bulunan az sayıda kadın çiftçinin de ankete katılmak istememesi nedeniyle sadece erkek üreticilerle anket yapılmış ve bunun neticesinde cinsiyet değişkeni araştırmanın bir sonraki bölümünde lojistik regresyon modeline dahil edilememiştir. Çiftçilerin yaş ortalamaları 47.77 yıl olup, 18 yıl ile 81 yıl arasında değişmektedir. Çiftçilerin eğitim seviyeleri orta düzeydedir. Çiftçilerin ortalama eğitim süreleri 7.85 yıl olup, 0 yıl ile 17 yıl arasında değişiklik göstermektedir. Araştırmada çiftçi ailesi genişliği de incelenmiştir. Araştırma bölgesinde ortalama çiftçi ailesi genişliği 4.25 kişi olup, 1 kişi ile 10 kişi arasındadır. Anket yapılan işletmelerin arazi varlıkları 0.5 da ile 620 da arasında değişmekte olup, ortalama 35.92 da'dır. Çiftçilerin \%27.20'si $(\mathrm{n}=65)$ herhangi bir kooperatife ortaktır. Geri kalan $\% 72.80$ 'inin ise herhangi bir kooperatif ortaklığ yoktur. Çiftçilerin \%31.40'1 $(\mathrm{n}=75)$ son üretim döneminde kredi kullanmış, \%68.60'1 ise $(\mathrm{n}=164)$ kullanmamıştır. Çiftçilerin tarım sigortası yaptırma durumları incelendiğinde, üreticilerin \%23.00'ünün (n = 55) tarım sigortası yaptırdığı, \%77.00'sinin $(\mathrm{n}=184)$ ise yaptırmadığı görülmektedir.

Üreticilerin \%10.00'u $(\mathrm{n}=24)$ serbest tarımsal danışmanlık hizmeti almakta, \%90.00'1 ise $(\mathrm{n}=215)$ almamaktadırlar. Üreticilerin son bir yılda katıldıkları tarımsal eğitim sayısı da incelenmiştir. Üreticilerin 
\%82.80'i $(\mathrm{n}=198)$ son bir yılda hiçbir tarımsal eğitime katılmamısken, \%17.20'si ise $(n=41) 1$ adet ile 5 adet arasında değişen sayıda eğitime katılmışlardır. Çiftçilerin \%46.00's1 $(\mathrm{n}=110)$ son bir ayda en az bir adet tarımsal kitap, broşür gibi yazılı materyal okumuş, $\% 54.00$ 'sı ise $(\mathrm{n}=129)$ okumamıştır.

Çiftçilerin Kredi Kullanımlarına Etki Eden Faktörler

Araştırma verilerine yönelik yapılan analiz sonucu elde edilen sonuçların yorumlanmasına geçilmeden önce, sonuçların yorumlanmasına etki edebileceğinden lojistik regresyon ile çoklu regresyon arasındaki bazı farklılıklara değinmek faydalı olacaktır. Çoklu regresyonda model kestiriminde en küçük kareler yöntemi (ordinary least square) kullanırken, lojistik regresyonda en çok olabilirlik (maximum likelihood) yöntemi kullanılmaktadır. Ayrıca model uyumu için kullanılan göstergelerde de farklılık bulunmaktadır.

Lojistik regresyonda $\mathrm{R}^{2}$ değeri bulunmazken, bu değere karşılık gelebilecek göstergeler bulunmaktadır. Bunun yerine bir model uyumu katsayısı olan LogLikehood - olabilirlik değeri, çoklu regresyondaki $\mathrm{R}^{2}$ değeri gibi düşünülebilmektedir. Ayrıca modele yönelik Cox\&Snell $\mathrm{R}^{2}$ ve Nagelkerke $\mathrm{R}^{2}$ değerleri, model tarafından bağımlı değişkende açıklanan varyansın iki farklı yoldan kestirilmesini temsil etmesi açısından önemli olup, değer karşılığı olmamakla birlikle yorumlama açısından çoklu regresyondaki $\mathrm{R}^{2}$ ile benzer şekilde yorumlanabilir (Hair et al., 1994; Alpar, 2011).

Çözümlenen modele ilişkin sonuçlara göre kikare değeri 111.580 olarak saptanmıştır ve elde edilen lojistik regresyon modeli istatistiki olarak anlamlıdır ( $\mathrm{p}<0.000)$. Modelin Loglikehood değeri 185.790, Cox\&Snell $R^{2}$ değeri 0.373 ve Nagelkerke $R^{2}$ değeri ise 0.523 olarak hesaplanmıştır.

Çiftçilerin tarımsal kredi kullanım kararlarına etki eden faktörlerin analiz edilmesi için kurulan ikili lojistik regresyon modelinin çözümlenmesi sonucu sabit terim başta olmak üzere, çiftçinin yaşı, hane genişliği, işlenen arazi miktarı, kooperatif ortaklığı, serbest tarım danışmanlığı alıp almama, son bir ayda tarımsal kitap, broşür gibi yazılı materyal okuma, son bir yılda katıldığı tarımsal eğitim programı sayısı ve sigorta yaptırma değişkenleri istatistiksel olarak anlamlı bulunmuştur. Çiftçilerin eğitim seviyeleri ise tarımsal kredi kullanımlarıyla doğru orantılı ancak istatistiksel olarak anlamsızdır (Çizelge 2).

Çizelge 2. Lojistik regresyon analizi sonuçları

\begin{tabular}{|l|c|c|c|c|c|c|}
\hline Değişken & B & S.E. & Wald & df & Sig. & Exp(B) \\
\hline Yaş & -0.035 & 0.016 & 4.520 & 1 & 0.033 & 0.966 \\
\hline Birey & 0.364 & 0.136 & 7.195 & 1 & 0.007 & 1.440 \\
\hline Arazi & 0.024 & 0.006 & 16.184 & 1 & 0.000 & 1.025 \\
\hline Kooperatif & 1.108 & 0.416 & 7.100 & 1 & 0.008 & 3.027 \\
\hline Danışman & -1.331 & 0.684 & 3.784 & 1 & 0.052 & 0.264 \\
\hline Yazılı Materyal & 0.860 & 0.418 & 4.234 & 1 & 0.040 & 2.363 \\
\hline Tarımsal Eğitim & -0.435 & 0.241 & 3.274 & 1 & 0.070 & 0.647 \\
\hline Eğitim & 0.100 & 0.061 & 2.651 & 1 & 0.104 & 1.105 \\
\hline Sigorta & 2.754 & 0.475 & 33.674 & 1 & 0.000 & 15.711 \\
\hline Sabit & -3.594 & 1.228 & 8.566 & 1 & 0.003 & 0.027 \\
\hline
\end{tabular}


Çiftçilerin yaşı ile kredi kullanımları arasında istatistiksel olarak anlamlı ve negatif bir ilişki mevcuttur. Yaş değişkenine ait katsayı -0.035 olarak hesaplanmıştır. Buna göre çiftçilerin yaşı arttıkça kredi kullanma olasılıkları azalmaktadır. Diğer bir değişle genç çiftçilerin kredi kullanma olasılıkları daha yüksektir. Bunun başlıca sebebi araştırma bölgesinde yaşlı çiftçilerin belli bir sermaye birikimine sahip olmalarından dolayı, tarım işletmesi için gerekli masrafları öz sermayeleri ile karşılayabiliyor olmalarıdır. Buna karşılık tarımsal üretime henüz yeni başlamış olan genç çiftçiler bir yandan tarım işletmesinin masraflarını karşılamak, bir yandan da henüz yeni bir aile kurmalarından dolayı aile giderlerini karşılamak durumundadırlar. Ayrıca genç çiftçiler daha yenilikçi olma eğilimindedirler (Sezgin ve ark., 2010). Yeni teknolojilerin takip edilerek, bunların uygulamaya geçirilmesi de belli bir yatırım gerektirmektedir. Henüz yeterli sermaye birikimine sahip olmayan bu genç çiftçiler, tarım işletmeleri için gerekli yatırımları yapmak ve işletme masraflarını karşılamak amacıyla tarımsal krediye başvurmaktadırlar. Bu sonuç Agbo et al. (2015) tarafından desteklenmektedir. Ancak daha önce yapılan bazı çalışmalarda farklı sonuçlar da bildirilmiştir. Aksoy ve ark. (2010) araştırmalarında çiftçilerin kredi kullanımları ile yaşları arasında anlamlı bir ilişki bulunmadığını, Filli et al. (2015) ise balık üreticilerinin yaşları ile kredi kullanımları arasında pozitif bir ilişki bulunduğunu bildirmişlerdir.

Araştırma sonuçlarına göre çiftçi ailesi genişliği ile tarımsal kredi kullanımı arasında pozitif ve istatistiksel olarak anlamlı bir ilişki vardır. İşlenen araziden yararlanan çiftçi ailesinin genişliği arttıkça, çiftçilerin aile ihtiyaçlarını karşılamak amacıyla daha fazla üretim yapması için tarımsal kredi kullanımı da artmaktadır. Diğer bir deyişle birey sayısı az olan küçük aileler, finansal ihtiyaçlarını kendi tarımsal gelirleri ve sermaye birikimleriyle karşılayabilmektedirler. Çiftçi ailesi genişliği ile kredi kullanımı arasındaki pozitif ilişkinin bir diğer sebebi de, çiftçi ailesi genişledikçe tarımsal aktiviteler de genişlemekte ve çeşitlenmektedir. Birey sayısı artan aile hayvansal üretim, meyve ve sebze üretimi ile diğer tarımsal faaliyetlere de daha fazla yönelebilmektedir. $\mathrm{Bu}$ durum ise birey sayısı artan ailenin sermaye ihtiyacını ve dolayısıyla kredi kullanımını artırmaktadır. Bu araştırma bulgusu daha önce çiftçi ailesinin genişliği ile tarımsal kredi kullanımı arasındaki ilişkinin incelenmesi amacıyla yapılan bazı araştırma sonuçları ile örtüşmektedir (Aksoy ve ark., 2010; Agbo et al., 2015; Saqip et al., 2017). Ancak Hananu et al (2015) çiftçi ailesi genişliği ile tarımsal kredi kullanımı arasında negatif bir ilişki bildirmiştir.

Bir diğer önemli araştırma bulgusu işlenen arazi miktarı ile kredi kullanımının pozitif ve istatistiksel olarak anlamlı bir ilişki içerisinde olduğudur. Arazi Türk toplumunda bir sosyal statü unsuru olarak görülmektedir (Demirci ve ark., 2007). İşlenen arazi miktarına bağlı olarak çiftçinin üretim masrafları da artmaktadır. Ayrıca işlediği arazi miktarı artan çiftçi, yeni ve ileri teknolojileri de uygulamaya geçirmek imkanına sahip olmaktadır. Daha ileri teknolojileri ve tarımsal yöntemleri uygulama şansı olan çiftçilerin, masraflarında da artış eğilimi görülmekte ve bu durum çiftçinin finansal ihtiyaçlarını da artırmaktadır. Bunun sonucu olarak da arazi miktarı artan çiftçilerin kredi kullanma olasılıkları da artmaktadır. Literatürde bu bulguyu destekleyen çalışmalar mevcuttur (Baffoe and Matsuda, 2015; Gunes et al., 2016; Saqip et al., 2017). Ancak literatürde bu çalışmada bulunan sonuçla çelişen bildirimler de vardır (Dzadze et al., 2012).

Çiftçilerin tarımsal kredi kullanımını belirleyen bir diğer faktör de çiftçilerin kooperatif ortaklığıdır. Araştırma bulgularına göre herhangi bir kooperatife ortak olan çiftçilerin kredi kullanma olasılıkları, diğer çiftçilere göre daha yüksektir. Bu durumun birinci sebebi üreticilerin kooperatif ortaklığı ile sağladıkları teknik bilgi ve becerileri uygulamaya geçirme istekleri sonucu sermaye ihtiyaçlarının artması olarak görülmektedir. Ayrıca bazı çiftçilerin ortak oldukları kooperatif, hali hazırda kredi ihtiyaçlarını da karşıladıkları tarım kredi kooperatifleridir. Bu araştırma bulgusu Hananu et al. (2015) tarafından desteklenmektedir.

Serbest tarımsal danışmanlık hizmeti Türkiye için henüz yeni bir uygulamadır ve halen çiftçiler tarafından yeterince tanınmamaktadır. Bundan dolayı zaten yeterli sermaye birikimine sahip olmayan çiftçiler serbest tarımsal danışmanlık hizmetine sıcak yaklaşmamaktadırlar. Araştırma bölgesinde serbest tarımsal danışmanlık hizmeti alan çiftçilerin sermaye birikimi olarak kendine yeter bir düzeyde bulunmas1 nedeniyle, bu çiftçiler kredi ihtiyacı duymamaktadırlar. Buna bağlı olarak da yapılan analiz sonucunda çiftçilerin serbest tarımsal danışmanlık hizmeti almaları ile tarımsal kredi kullanımları arasında negatif ve istatistiksel olarak anlamlı bir ilişki tespit edilmiştir. $\mathrm{Bu}$ 
bulguya göre Mersin'de serbest tarımsal danışmanlık hizmeti alan çiftçilerin, diğer çiftçilere göre tarımsal kredi kullanma ihtimalleri daha düşüktür.

Çiftçilerin son bir ay içerisinde tarımsal kitap, broşür gibi yazılı materyal okumaları ile tarımsal kredi kullanımları arasında pozitif ve istatistiksel olarak anlamlı bir ilişki vardır. Yani son bir ay içerisinde tarımsal konularda yazılı materyal okuyan çiftçilerin, diğer çiftçilere göre kredi kullanma olasılıkları daha yüksektir. Araştırmada çiftçilerin son bir yılda katıldıkları tarımsal eğitim programı sayısı ile kredi kullanımları arasında ters yönlü ve istatistiksel olarak anlamlı bir ilişki tespit edilmiştir. Buna göre araştırma bölgesinde çiftçilerin son bir yılda katıldıkları tarımsal eğitim programı sayısı arttıkça tarımsal kredi kullanma olasılıkları azalmaktadır.

Araştırma sonuçlarına göre çiftçilerin eğitim seviyeleri ile tarımsal kredi kullanımları arasında istatistiksel olarak anlamlı bir ilişki tespit edilememiştir $(p=0.104)$. Ancak eğitim seviyesi ile tarımsal kredi kullanımı arasındaki ilişkiye dair katsayı pozitif bulunmuştur. $\mathrm{Bu}$ durum çiftçilerin eğitim seviyeleri arttıkça kredi kullanma olasılıklarının da artma eğiliminde olacağ 1 şeklinde yorumlanabilir. Konu ile ilgili daha önce gerçekleştirilen bazı araştırmalarda çiftçilerin eğitim seviyesi ile tarımsal kredi kullanımları arasında pozitif bir ilişki bildirilmiştir (Hananu et al., 2015).

Çiftçilerin sigorta yaptırmaları ile tarımsal kredi kullanımları arasında pozitif ve istatistiksel olarak anlamlı bir ilişki vardır. Buna göre tarım sigortası yaptıran çiftçilerin tarımsal kredi kullanma olasılıkları, tarım sigortası yaptırmayan çiftçilere göre daha yüksektir. Bunun sebebi kredi kuruşlarının kredilerinin geri dönüşünü garanti altına almak için tarımsal kredi sağladıkları çiftçiden ürünlerini tarım sigortaları kapsamına aldırmalarını istemeleridir. Bu sonuç Filli et al. (2015) tarafından da desteklenmektedir.

\section{KAYNAKLAR}

Agbo FU, Iroh II, Ihemezie EJ, 2015. Access to credit by vegetable farmers in Nigeria: A case study of Owerri Agricultural Zone of Imo State, Nigeria. Asian Journal of Agricultural Research, 9(4): 155 - 165 .

Aksoy A, Işık HB, İkikat Tümer E, 2010. Antepfıstığ işletmelerinde tarımsal kredi kullanımına etki eden faktörlerin analizi. Türkiye 9. Ulusal Tarım Ekonomisi Kongresi, 22 - 24 Eylül 2010, Şanliurfa.

\section{SONUÇ}

Kredi üretim, pazarlama ve diğer tarımsal faaliyetlerin geliştirilebilmesi için önemli bir unsurdur. $\mathrm{Bu}$ araştırmada çiftçilerin bazı sosyoekonomik özelliklerinin ve bilgi arama davranışlarının kredi kullanma kararlarını etkilediği belirlenmiştir. Araştırma sonuçlarına göre aile genişliği, işlenen arazi miktarı, kooperatif ortaklığı ve yazılı materyal okuma değişkenleri çiftçilerin tarımsal kredi kullanımlarını pozitif; çiftçinin yaşı, serbest tarım danışmanlığı hizmeti alıp almama ve son bir yılda katıldı ğı tarımsal eğitim programı sayısı değişkenleri ise negatif yönde etkilemektedir. Çiftçilerin eğitim seviyeleri ile kredi kullanım kararları arasında ise anlamlı bir ilişki bulunamamıştır.

Araştırma sonuçlarına göre çiftçilerin kooperatif ortaklığ 1 ve yazılı materyal okuma durumları ile kredi kullanımları arasında pozitif bir ilişki vardır. Bu sebeple kredi kullanımın geliştirilmesi ve kredinin uygun alanlara yönlendirilebilmesi için araştırma bölgesinde tarımsal kooperatif ve çiftçilerin tarımsal kitap, broşür gibi yazılı materyal okumaları teşvik edilmelidir. Ayrıca kooperatifler aracılığıyla yürütülecek programlarla tarımsal kredilerin en uygun alanlara yönlendirilmesi de sağlanabilir.

Çalışmada çiftçilerin işledikleri arazi miktarı arttıkça kredi kullanma olasılıklarının da artacağı tespit edilmiştir. $\mathrm{Bu}$ kapsamda arazi toplulaştırması çalışmaları ve arazi bölünmesinin önüne geçebilmek için alınan önlemler, tarımsal kredi piyasalarının da hareketlenmesine katkı să̆layabilir.

Benzer araştırmaların Türkiye'nin diğer bölgelerinde de yapılması ile bu araştırmanın sonuçlarının geçerliliği artırılabilir ve bu durum mevcut araștırma sonuçları ile birlikte özel ve kamu bankaları gibi kredi kuruluşlarının hedef kitlelerini belirlemede yardımcı olabilir.

Alpar R, 2011. Uygulamalı Çok Değişkenli İstatistiksel Yöntemler. Üçüncü Baskı, Ankara, Türkiye. 599 - 611 s.

Baffoe G, Matsuda H, 2015. Understanding the Determinants of Rural Credit Accessibility: The Case of Ehiaminchini, Fanteakwa District, Ghana. Journal of Sustainable Development, 8(6): 183 - 195.

Bozoglu M, Ceyhan V, 2007. Measuring the technical efficiency and exploring the inefficiency determinants of vegetable farms in Samsun province, Turkey. Agricultural Systems, 94: 649 - 658. 
Bülbül M, 2006. Tarımsal İşletmelerin Finansmanı. Ankara, Türkiye. $1-20 \mathrm{~s}$.

Demirci R, Tanrıvermiş H, Aliefendioğlu Y, 2007. Türkiye'de arazi yönetimi ve piyasası: temel özellikleri, yasal ve kurumsal düzenlemeler, sorunlar ve değerleme çalışmaları üzerine etkileri. Üçüncü Sektör Kooperatifçilik, 4(42): 38 - 63.

Doğan Z, Arslan S, Berkman AN, 2015. Türkiye'de tarım sektörünün iktisadi gelişimi ve sorunları: Tarihsel bir bakış. Niğde Üniversitesi İktisadi ve İdari Bilimler Fakültesi Dergisi, 8(1): 29 - 41 .

Dzadze P, Aidoo R, Nurah GK, 2012. Factors determining access to formal credit in Ghana: A case study of smallholder farmers in the Abura-Asebu Kwamankese district of central region of Ghana. Journal of Development and Agricultural Economics, 4(14): 416-423.

Engürülü B. 2017. Dünyada ve Türkiye'de tarım. Tarım Reformu Genel Müdürlüğü, Tarım Sigortaları ve Doğal Afetler Daire Başkanlı̆̆ı (Basılmamış Sunum).

Filli FB, Onu JI, Adebayo EF, Tizhe I, 2015. Factors influencing credits access among small scale fish farmers in Adamawa State, Nigeria. Journal of Agricultural Economics, Environment and Social Sciences, 1(1): 46 - 55.

Gunes E, Movassaghi H, 2017. Agricultural Credit Market and Farmers' Response: A Case Study of Turkey. Turkish Journal of Agriculture - Food Science and Technology, 5(1): 84 - 92.

Gunes E, Movassaghı H, Ozer OO, 2016. Determinants of credit use in Turkish agriculture. International Journal of Research in Agricultural Sciences, 3(4): 216 - 222.
Hair FJ, Anderson JR, Tatham RZ, Black WC, 1994. Multivariate Data Analysis. Third Edition, New York, USA. 413 - 434 p.

Hananu B, Abdul-Hanan A, Zakaria H, 2015. Factors influencing agricultural credit demand in Northern Ghana. African Journal of Agricultural Research, 10(7): 645 - 652.

İzmir Ticaret Borsası, 2014. Rakamlarla Türkiye Tarımı. İzmir Ticaret Borsası Ar-Ge Müdürlüğü, İzmir, Türkiye. 6 s.

Kalaycı Ş, 2008. SPSS Uygulamalı Çok Değişkenli İstatistik Teknikleri. İstanbul, Türkiye. 62 - 78 s.

Kizilaslan H, Adiguzel O, 2007. Factors affecting credit use in agricultural business concerns in Turkey. Res. J. Agric. Biol. Sci, 3(5): 409-417.

Özçelik A, Güneş E, Artukoğlu MM, 2005. Türkiye'de tarımsal kredi: sözleşmeli tarım ve üretici örgütleri üzerinden kredi uygulamaları. Ziraat Mühendisliği VI. Teknik Kongresi, 3- 7 Ocak 2005, Ankara.

Saqip SE, Kuwornu JKM, Panezia S, Ali U, 2017. Factors determining subsistence farmers' access to agricultural credit in flood-prone areas of Pakistan. Kasetsart Journal of Social Sciences. https://doi.org/10.1016/j.kjss.2017.06.001

Sezgin A, Kaya Erem T, Külekçi M, Kumbasaroğlu H, 2010. Tarımsal Yeniliklerin Benimsenmesinde Etkili Olan Faktörlerin Analizi: Erzurum İli örneği, Türkiye 9. Ulusal Tarım Ekonomisi Kongresi, 22 - 24 Eylül 2010, Şanlıurfa.

Terin M, Güler İO, Aksoy A. 2014. Türkiye'de tarımsal üretim ile tarımsal kredi kullanımı arasındaki nedensellik ilişkisi. Iğdır Üni. Fen Bilimleri Enst. Der. / Iğdır Univ. J. Inst. Sci. \& Tech., 4(1): 67 - 72 . 